\title{
Reliability optimization in a four-echelon green closed-loop supply chain network considering stochastic demand and carbon price
}

\author{
Mahmood Nosrati ${ }^{a}$ and Alireza Arshadi Khamseh ${ }^{b^{*}}$
}

${ }^{a}$ Department of Industrial Engineering, Faculty of Engineering, Kharazmi University, Tehran, Iran

${ }^{b}$ Associate Professor Department of International Logistics and Transportation, Faculty of Economics Administration and Social Sciences, Istanbul \author{
Gelisim University, Turkey

\section{H R O N I C L E}

\begin{tabular}{l}
\hline Article history: \\
Received January 29, 2020 \\
Received in revised format March \\
27,2020 \\
Accepted May 92020 \\
Available online \\
May 92020 \\
\hline Keywords: \\
Structural reliability theory \\
Carbon trading \\
Stochastic Bi-Objective \\
programming \\
NSGA-II \\
Green supply chain network \\
design
\end{tabular}

\begin{abstract}
A B S T R A C T
In recent years, one of the goals of any company is to increase overall production and process reliability. Hereupon supply chain reliability has been gaining growing attention and provides a technical framework for quantifying supply chain risks and uncertainties. In this paper, supply chain reliability was investigated in a two-stage stochastic programming model to design reliable closed-loop green four-echelon forward/backward supply chain networks. The purpose of this model was to maximize the total reliability of the supply chain based on the structural reliability theory. Our proposed model also minimized the cost of the supply chain by definition of recycling centres and the cost of penalizing unauthorized carbon emission and damages. The model optimized the locations of factories, warehouses, and recycling centres considering stochastic modes for demands and carbon price, as well as the flow between different sectors and the optimal orders. As the proposed model was a mixed-integer nonlinear problem, both e-constraint method and the metaheuristic algorithm (NSGA-II) were used in different scales and the sensitivity analysis was performed for critical parameters.
\end{abstract}

(C) 2020 by the authors; license Growing Science, Canada.

\section{Introduction}

In today's modern world, to survive in the competitive production market, providing products and services with the highest quality, lowest cost, and in an acceptable time is critical. To achieve this, the supply chain viewpoint is used in business and commerce where every supply chain can include various components such as suppliers, factories, distributors, retailers, consumers, and recycling centers. The strategic supply chain decisions include finding the supply chain configuration so that the flow of materials and goods effectively and appropriately interconnected between supply chain components. These decisions include deciding the number, location, capacity, and technology of production and storage inputs. Therefore, strategic decisions are of great importance. Implementing strategic decisions requires large expenditures. Changes after the establishment of factories and distribution centers will be hard and costly. Therefore, strategic decisions must perform in such a way to minimize distances from the optimum situation over time and changing conditions. Choosing the goal and understanding the current and future conditions is a significant contribution to making strategic decisions better. In

\footnotetext{
* Corresponding author

E-mail address: akhamseh@gelisim.edu.tr (A. Arshadi Khamseh)

C 2020 by the authors; licensee Growing Science.

doi: $10.5267 /$ j.uscm.2020.5.002
} 
the design of the supply chain network traditionally, the focus has only been on cost reduction (Dehghanian \& Mansour, 2009; Nickel et al., 2012). However, with increasing concerns about environmental degradation as well as the adoption of different regulatory laws, managers should consider the green factor in addition to financial matters (Fahimnia, 2015). In fact, the use of the green supply chain allows companies and organizations to perform well in both economic and environmental dimensions (Ramudhin et al., 2010).

However, the greening of the supply chain is not simple and requires a new attitude, as well as a complete awareness of the current supply chain conditions, which requires reviewing activities and redefining the supply chain network (Bidhandi \& Yusuff, 2011). One of the ways to consider the green factor in the supply chain is to consider carbon cost and determine the permission amount of carbon in the production (Zakeri et al., 2015). In these circumstances, a penalty is assigned to produce the unauthorized surplus.

Moreover, as the outsourcing and expansion of organizations quicken, the intricacy of the supply chain also increases. This case magnifies system risk and uncertainty that results from factors such as lead time, natural disasters, instability of procurement, and all that disrupt production and distribution. Thus, effective management of these factors is crucial to the stable and efficient performance of the supply chain. (Ha et al., 2018).

In this paper, the total reliability of a closed-loop green supply chain with stochastic demand and carbon price modeled by two-stage stochastic planning are evaluated using structural reliability theory. We consider a two-stage stochastic optimization model where location, capacity, and production technology will be determined for all facilities first of all, and in the second phase, the allocation and distribution of products will be determined. Also, due to the uncertainty of carbon price and product demand, the solution method is to put the expectation of uncertain parameters and solving a certain problem (Hugo \& Pistikopoulos, 2005). For this purpose, a restricted number of scenarios are considered for product demand and carbon price (Rezaee et al., 2017). Modeling based on different scenarios helps decision-makers study the uncertainties of the model parameters by considering different scenarios (Hamidieh et al., 2018). The solutions obtained in this case are not necessarily optimal and can be far from the optimal answer or even are impossible for some scenarios (Ramudhin et al., 2010).

In the following sections, we have: Literature review that presented a summary of published related models, highlighting the implications of this research and its status in the subject literature in section 2. The problem definition and its mathematical modeling has been defined in Section 3 where in section 4 problem-solving methods have been discussed, and numerical examples and results were described in Section 5. The sensitivity analysis of the important parameters of the model has been performed in Section 6. Finally, in section 7 conclusion and further studies have been given.

\section{Literature review}

A survey of location models suggests that over $82 \%$ of past works considered the demand and cost parameters definitively (Melo et al., 2009). The recent research trend seems to focus on the uncertainty of demand (Bidhandi \& Yusuff, 2011). Presented models can be considered based on stochastic parameters, supply chain scale (i.e., number of levels), plurality of scheduling periods (one or multicycle), product flow considerations (forward or backward), the type of target functions (e.g. lowering costs, maximizing profits, earnings, or service levels), and different solving approaches (Baghalian et al., 2013).

Abdullah et al. (2012) presented a single-objective model in which environmental issues introduced into the model by using the modeling of polluting emissions through the carbon trading market in the objective function. They also considered the emission levels of distribution and supply by providing a comprehensive model. Guillén-Gosálbez and Grossmann (2009) were the pioneers who introduced the 
uncertainty of environmental parameters into a mathematical model. They defined uncertainty in the contamination for production or transportation of each commodity in different parts of a supply chain. Their focus was on a chemical supply chain that was carried out as a mixed-integer nonlinear programming model, which maximized profitability and minimized chain contamination.

Rezaei et al. (2017) introduced a two-stage stochastic model in which demand and carbon prices are probable. In this model, decisions made in two stages. Firstly, location, capacity, and production technology were determined for all facilities, and other choices on allocation and distribution of products were taken in the second phase.

Torabi et al. (2019) presented a new multi-objective model by considering the network's lack and reworking and carbon emissions in the two-stage green supply chain problem. Tsao et al. (2018) suggested a multi-objective SCND model taking into consideration of carbon footprint under uncertain conditions. The model minimized network-oriented costs and environmental impacts and maximized social benefits. Their model attempted to make decisions concerning the selection of production technologies and materials and determine the number and locations of factories and shipping centers and the number of products to be transported between facilities. They considered customer demand uncertainty by using stochastic variables.

Chalmardi and Camacho-Vallejo (2019) proposed a bi-level sustainable supply chain network design in which they considered all the possible levels, such as government and manager that have essential roles in decision-making. In the first level of the model, relevant to government, the objective function is to minimize the total environmental impacts resulted from activities of the supply chain. At the same time, they tried to cause an impact in the SCND by offering financial incentives (subsidies) and by encouraging the supply chain's manager to use cleaner technologies. The second level consists of the supply chain manager, which seeks to minimize the costs of the supply chain.

Kuo et al. (2018) introduced a supply chain network considering cost and emission as objective functions and measures the carbon footprint, wherein the greenhouse gases emissions data are based on carbon footprint standards. They considered the emissions of raw material, factories, and transportation to quantify environmental contamination. Jerbia et al. (2018) developed a closed-loop supply chain network with various recycling options. First, they formulated the deterministic problem and then developed a stochastic version of the model to account for the high uncertainties faced by companies. They used a scenario-based approach to model the uncertainties of return rates, incomes, costs.

Failure of a system could disrupt its different levels and can be detrimental to the society and the environment. There would be a probability failure rate in any facilities which causes disruption during the. Atoei et al. (2013) remarked factors like adverse weather conditions, worker strikes, economic crisis, destruction or terrorist attacks, and alteration in ownership of the system that may cause the entire set of facilities or services to malfunction. They proposed the reliability in the network design of the supply chain by considering random disruptions in both distribution centers and suppliers and consider a range of reliability instead of using binary variables.

Zaitsev (2012) developed strategies for quantitatively analysis the hazards of supply chains and to avoid fundamental failures by using reliable engineering. They defined reliability as the probability that a product will work properly for a period and would be replaced with the risk probability in the supply chain.

Ha et al. (2018) proposed a brief and specific math definition for supply chain reliability and based on it, the relevant functions, such as risk, cumulative risk, and availability, described at the level of components of production. Also, they paid to provide structural reliability models such as series, 
parallel, parallel series and parallel series using the reliability theory at the system level that was in line with the leading supply chain activities.

Daehy et al. (2019) explained a statistical method for measuring the reliability rate of each part in the system and also the whole supply chain. Further, they define a mathematical model to improve the reliability of the supply chain and the minimization of cost components.

Nosrati and Arshadi-Khamseh (2020) studied a reliability optimization model in the hybrid vehicle routing problem with two objective functions as minimizing costs and maximizing the reliability of the whole system. Their model involves alternative routes with different reliability. They used the series structure theory for routes to model reliability objective function. Table 1 presents the subjects and the status of the present research briefly.

\section{Table 1}

Related models review in supply chain network design

\begin{tabular}{|c|c|c|c|c|c|c|c|c|c|c|}
\hline \multirow[t]{2}{*}{ Reference articles } & \multicolumn{4}{|c|}{ Modeling type } & \multicolumn{2}{|c|}{ SC type } & \multicolumn{2}{|c|}{ NOF } & \multirow{2}{*}{ 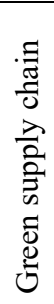 } & \multirow[b]{2}{*}{ 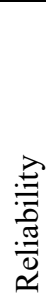 } \\
\hline & $\begin{array}{l}\frac{\lambda}{0} \\
.00 \\
\frac{0}{0} \\
0\end{array}$ & 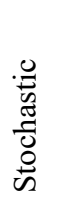 & 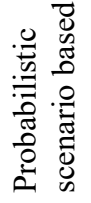 & 总 & 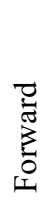 & $\begin{array}{l}0 \\
0 \\
0 \\
\frac{1}{0} \\
\frac{0}{0} \\
0 \\
\frac{0}{U}\end{array}$ & $\begin{array}{l}\frac{0}{000} \\
\stackrel{\Xi}{\Xi}\end{array}$ & $\stackrel{\Xi}{\Xi}$ & & \\
\hline Guillén et al. (2009) & & $\sqrt{ }$ & $\sqrt{ }$ & $\sqrt{ }$ & $\sqrt{ }$ & & $\sqrt{ }$ & & $\sqrt{ }$ & \\
\hline $\begin{array}{l}\text { Abdallah et al. } \\
(2012)\end{array}$ & $\sqrt{ }$ & & & & $\sqrt{ }$ & & $\sqrt{ }$ & & $\sqrt{ }$ & \\
\hline Rezaee et al. (2017) & & $\sqrt{ }$ & $\sqrt{ }$ & $\sqrt{ }$ & $\sqrt{ }$ & & $\sqrt{ }$ & & $\sqrt{ }$ & \\
\hline Tsao et al. (2018) & & $\sqrt{ }$ & $\sqrt{ }$ & $\sqrt{ }$ & $\sqrt{ }$ & & & $\sqrt{ }$ & $\sqrt{ }$ & \\
\hline Torabi et al. (2019) & $\sqrt{ }$ & & & & & $\sqrt{ }$ & & $\sqrt{ }$ & $\sqrt{ }$ & \\
\hline Chalmardi (2019) & & & $\sqrt{ }$ & & $\sqrt{ }$ & & & $\sqrt{ }$ & $\sqrt{ }$ & \\
\hline Kuo et al. (2018) & $\sqrt{ }$ & & & & $\sqrt{ }$ & & & $\sqrt{ }$ & $\sqrt{ }$ & \\
\hline Jerbia et al. (2018) & & $\sqrt{ }$ & $\sqrt{ }$ & $\sqrt{ }$ & & $\sqrt{ }$ & $\sqrt{ }$ & & & \\
\hline Our work & & $\sqrt{ }$ & $\sqrt{ }$ & $\sqrt{ }$ & & $\sqrt{ }$ & & $\sqrt{ }$ & $\sqrt{ }$ & $\sqrt{ }$ \\
\hline
\end{tabular}

Rework and recycling are primary reasons for reverse logistics and green supply chain that reduce the cost of production and other environmental problems (Singh et al., 2014). Innovations of this paper, in comparison to the other previous models in the literature are reliability optimization and recycling centers which are the crucial parts of green supply chain.

To add recycling centers, here we have three practical approaches as follows:

1. Recycling centers will be fixed and related manufacturing sites should be explored.

2. The manufacturing sites are fixed and the problem is finding the recycling sites based on it.

3. Neither the manufacturing centers nor recycling sites are not pre-determined.

For being more realistic in our problem definition and including much flexibility in it, location of manufacturing sites and recycling centers are not pre-determined and for reduction of the cost, model attempts to achieve a balance in the selection of candidate locations for recycling centers and factories. Here the carbon emissions parameters and reliability have been considered for the recycling centers. Furthermore, a pre-defined waste percentage is considerable and these wastages will be directed to the disposal sites directly. 


\section{Problem statement}

Here we consider a four echelon forward/backward supply chain including suppliers, manufacturing factories, warehouses, final consumers, and recycling centers. In this supply chain, various commodities are produced, and every manufacturing center has its specific technology that affects the cost of production and releases carbon. The goal here is to develop a two-stage stochastic model for designing and configuring a four-echelon closed loop supply chain network. Decisions of the first stage, called strategic decisions, include:

- Raw material supplier selection

- Determine the location and capacity of production and storage

- Determining factory production technology

- Locate economic sites for recycling centers

The general form of stochastic planning is as follows:

$$
\min z=c x+E_{\xi} Q(x, \xi)
$$

s.t.

$$
A x=b \text { and } x \geq 0
$$

where $x$ is the decision variable of the first stage and $c$ is the vector of coefficients of $x$ in the objective function of the first step. Also, $E_{\xi} Q(x, \xi)$ is an expectation of different scenarios. $A$ and $b$ are respectively matrices of the coefficients of variables in the set of constraints and the right vector. Given that the number of scenarios is limited, for example, $k$, the generalization of the overall two-stage stochastic planning model presented as follows (Birge \& Louveaux, 2011).

$$
\min c^{T} x+\sum_{k=1}^{k} p_{k} q_{k}^{T} y_{k}
$$

s.t.

$$
\begin{aligned}
& A x=b \\
& T_{k} x+W y_{k}=h_{k}, \quad k=1, \ldots, K \\
& x \geq 0, y_{k} \geq 0, \quad k=1, \ldots, K
\end{aligned}
$$

where $y_{k}, q_{k}^{T}, p_{k}$ are respectively the probability of occurrence of the scenario $k$ and the decision variable of the second stage. Also, the matrices $T, W, h$ are respectively the right vector of the problem in the second stage, the sum of the coefficients of the problem variables in the second stage, and the matrix of the coefficients of the first stage variables in the second stage.

The communication types of system components are crucial to assess system reliability. In reliability theory, a graphical illustration of the relation of system components called reliability block diagram is the start of analyzing, which is constructed according to a rational construction (Ha et al., 2018). Fig. 1 shows the reliability block diagram of our supply chain structures to evaluate the complete supply chain reliability. 


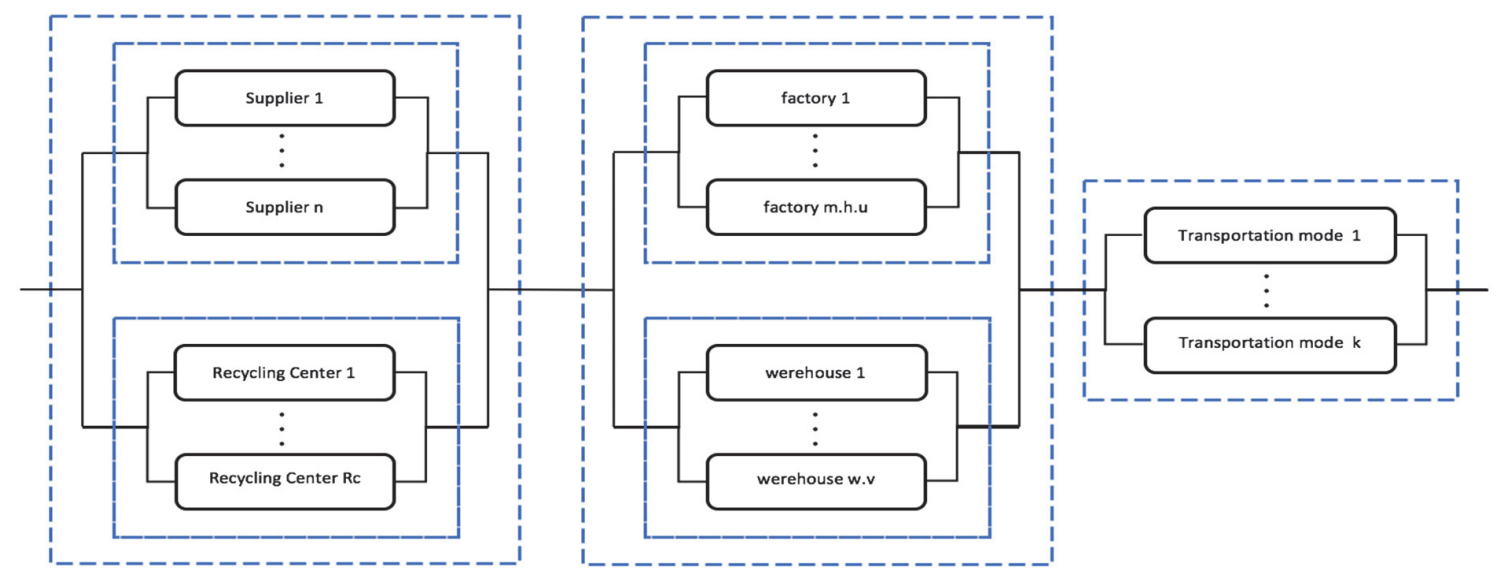

Fig. 1. Reliability block diagram of problem

The indexes, parameters, and decision variables utilized in the model are defined as follows:

Index

$i \quad$ Product

$r \quad$ Raw material

n Supplier

$m \quad$ Manufacturing factory

h Production technology

$u \quad$ Factory Capacity

w Warehouse

$v \quad$ Warehouse capacity

$k \quad$ Transport mode

Rc Recycling centers

j $\quad$ Final consumer

$s \quad$ Scenario

\section{Parameters}

$\pi_{S} \quad$ Cost of carbon in scenario $\mathrm{S}$

$d_{i j s} \quad$ The forecasted consumer demand $\mathrm{j}$ for the product $\mathrm{I}$ in scenario $\mathrm{s}$

cap Maximum authorized carbon released (ton)

$f_{m h u} \quad$ The fixed cost of deploying factory $\mathrm{m}$ with technology $\mathrm{h}$ and capacity $\mathrm{U}$

$f_{w v}^{\prime} \quad$ The fixed cost of deploying warehouse $\mathrm{w}$ with capacity $\mathrm{v}$

$f_{n}^{\prime \prime} \quad$ The Fixed cost of selecting supplier $n$

$f_{R c}^{\prime \prime \prime} \quad$ The fixed cost of deploying the recycling center Rc

$\mathrm{cm}_{\text {imh }}$ The cost of producing a unit of product $\mathrm{i}$ with technology $\mathrm{h}$ at the factory $\mathrm{m}$ 
$c m_{r R c}^{\prime} \quad$ The cost of recycling material $\mathrm{r}$ at recycling center $\mathrm{Rc}$

$C S_{r n m}$

The cost of purchasing a unit raw material $r$ from the supplier $n$ for processing at the factory

$c t_{\text {imwk }}$ Per unit cost of trucking product i from factory $\mathrm{m}$ to warehouse $\mathrm{w}$ with vehicle mode $\mathrm{k}$

$c t_{i w j k}^{\prime} \quad$ Per unit cost of trucking product $\mathrm{i}$ from warehouse $\mathrm{w}$ to consumer $\mathrm{j}$ using transport mode $\mathrm{k}$

$c t_{i m j k}^{\prime \prime} \quad$ Per unit Cost of trucking product $\mathrm{i}$ from factory $\mathrm{m}$ to consumer $\mathrm{j}$ using transport mode $\mathrm{k}$

$c t_{r m R c}^{\prime \prime \prime}$ Transportation cost of the material $\mathrm{r}$ between the factory $\mathrm{m}$ and the recycling center Rc

$\rho_{\text {in }} \quad$ The processing time of a unit of the product $\mathrm{i}$ with technology h (h)

$\rho_{i}^{\prime} \quad$ The volume of a unit of product i (cubic meter)

$\alpha_{r i} \quad$ The required amount of raw material $\mathrm{r}$ to produce a unit of product $\mathrm{i}$

$c_{m h u} \quad$ The capacity of production (time) at factory $\mathrm{m}$ with technology $\mathrm{h}$ and capacity $\mathrm{u}$

$c_{w v}^{\prime} \quad$ The capacity of space in warehouse $\mathrm{w}$ with capacity $\mathrm{v}$ (cubic meter)

$c_{r n}^{\prime \prime} \quad$ the Capacity of raw material $\mathrm{r}$ in supplier $\mathrm{n}(\mathrm{kg})$

$l b_{m w k} \quad$ Minimum authorized transport volumes from factory $\mathrm{m}$ to warehouse $\mathrm{w}$ by transport mode $\mathrm{k}\left(\mathrm{m}^{3}\right)$

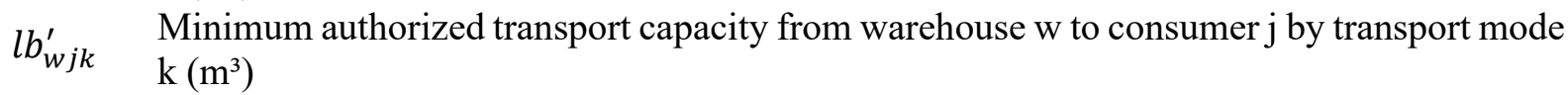

$l b_{m j k}^{\prime \prime} \quad$ Minimum authorized transport volumes from factory $\mathrm{m}$ to consumer $\mathrm{j}$ by transport mode $\mathrm{k}$ $\left(\mathrm{m}^{3}\right)$

$u b_{m w k}$ Maximum authorized transport volumes from factory $\mathrm{m}$ to warehouse $\mathrm{w}$ by transport mode $\mathrm{k}\left(\mathrm{m}^{3}\right)$

$u b_{w j k}^{\prime} \quad$ Maximum authorized transport capacity from warehouse $\mathrm{w}$ to consumer $\mathrm{j}$ by transport mode $\mathrm{k}\left(\mathrm{m}^{3}\right)$ $u b_{m j k}^{\prime \prime} \quad \begin{aligned} & \text { Maximum authorized transport volumes from factory } \mathrm{m} \text { to consumer } \mathrm{j} \text { by transport mode } \mathrm{k} \\ & \left(\mathrm{m}^{3}\right)\end{aligned}$

$e m_{\text {imh }}$ Estimated carbon emissions for the production of a unit of product $\mathrm{i}$ with technology $\mathrm{h}$ at the factory $m$ (ton)

$e m_{r R c}^{\prime} \quad$ Estimated carbon emissions for recycling a unit of material $\mathrm{r}$ at the recycling center $\mathrm{Rc}$ (ton)

$e t_{i m w k}$ Estimated carbon emissions for carrying a unit of product $\mathrm{i}$ from factory $\mathrm{m}$ to warehouse $\mathrm{w}$ by transport mode $\mathrm{k}$ (ton)

$e t_{i w j k}^{\prime}$ Estimated carbon emissions for carrying a unit of product $\mathrm{i}$ from warehouse $\mathrm{w}$ to the consumer $\mathrm{j}$ by transport mode $\mathrm{k}$ (ton)

$e t_{i m j k}^{\prime \prime} \quad$ Estimated carbon emissions for carrying a unit of product $\mathrm{i}$ from factory $\mathrm{m}$ to consumer $\mathrm{j}$ by transport mode $\mathrm{k}$ (ton)

$e t_{r m R c}^{\prime \prime \prime}$ Estimated carbon emissions for carrying material $\mathrm{r}$ from factory $\mathrm{m}$ to recycling center Rc

$R F_{m h u} \quad$ Reliability of Factory $\mathrm{m}$ with technology $\mathrm{h}$ and capacity $\mathrm{u}$

$R F_{w v}^{\prime} \quad$ Reliability of warehouse w with capacity $\mathrm{v}$

$R F_{n}^{\prime \prime} \quad$ Reliability of Supplier $\mathrm{n}$

$R F_{R c}^{\prime \prime \prime} \quad$ Reliability of Recycling Center Rc

$R k_{k} \quad$ Reliability of transportation mode $\mathrm{k}$ 
$l t_{m h} \quad$ The fixed cost conversion parameter of deploying factory $m$ with technology $\mathrm{h}$ to its annual equivalent

$l t_{w}^{\prime} \quad$ The fixed cost conversion parameter of deploying warehouse $\mathrm{w}$ to its annual equivalent

$l t_{R c}^{\prime \prime} \quad \begin{aligned} & \text { The fixed cost conversion parameter of deploying recycling center } \mathrm{Rc} \text { to its annual } \\ & \text { equivalent }\end{aligned}$

$p c_{i j} \quad$ Penalty cost for the lack of a unit of product $\mathrm{i}$ for consumer $\mathrm{j}$

$p s_{s} \quad$ Chance of scenario $\mathrm{s}$

$b \quad$ Total budget for facilities founding

$\beta \quad$ Percentage of raw material received from recycling centers

$\lambda \quad$ Percentage of waste generated from the production

Continues decision variables

$Q_{i m h s} \quad$ The amount of product $\mathrm{i}$ that is produced in the factory $\mathrm{m}$ and with technology $\mathrm{h}$ in the

$Q_{r m R c s}^{\prime}$ The amount of material $\mathrm{r}$ sent from the factory $\mathrm{m}$ to the recycling center Rc

$R_{\text {rnms }} \quad$ Amount of raw material $\mathrm{r}$ delivered from the supplier $\mathrm{n}$ to the factory $\mathrm{m}$ in the scenario $\mathrm{s}$

$L_{i m w k s}$ Amount of product $\mathrm{i}$ that send from factory $\mathrm{m}$ to warehouse $\mathrm{w}$ by transport mode $\mathrm{k}$ in scenario $\mathrm{s}$

$L_{i w j k s}^{\prime} \quad$ Amount of product $\mathrm{i}$ that send from the warehouse $\mathrm{w}$ to the consumer $\mathrm{j}$ and by transport mode $\mathrm{k}$ in scenario $\mathrm{s}$

$L_{i m j k s}^{\prime \prime} \quad$ Amount of product $\mathrm{i}$ that send from the factory $\mathrm{m}$ to the consumer $\mathrm{j}$ by transport mode $\mathrm{k}$ in

$O_{i j s} \quad$ Amount of product $\mathrm{i}$ deficiency in consumer $\mathrm{j}$ in scenario $\mathrm{s}$

$E_{S} \quad$ Pure number of carbon stocks traded in scenario s

Binary decision variables

$F_{m h u} \quad$ Equal to 1 if the factory $\mathrm{m}$ with capacity $\mathrm{u}$ and technology $\mathrm{h}$ founded; otherwise, 0

$F_{w v}^{\prime} \quad$ Equal to 1 if the warehouse w with capacity $\mathrm{v}$ founded; otherwise, 0

$F_{n}^{\prime \prime} \quad$ Equal to 1 if the supplier $\mathrm{n}$ selected; otherwise, 0

$F_{R c}^{\prime \prime \prime} \quad$ Equal to 1 if the recycling center Rc selected; otherwise, 0

$G_{m w k s}$ Equal to 1 if the current between the factory $\mathrm{m}$ and the warehouse w by transport mode k is available; otherwise, 0

$G_{w j k s}^{\prime} \quad$ Equal to 1 if the current between the warehouse w and the consumer $\mathrm{j}$ by transport mode k is available; otherwise, 0

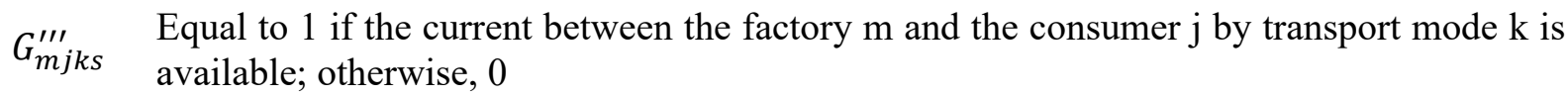

The following is an explanation of the problem mathematical model. 


$$
\begin{aligned}
& \min Z 1=\sum_{m} \sum_{h} \sum_{u}\left(l t_{m h} f_{m h u}\right) F_{m h u}+\sum_{w}^{\text {M. Nosrati and A. Arshadi Khamseh /Uncertain Supply Chain Management 8 (2020) }}\left(l t_{w}^{\prime} f_{w v}^{\prime}\right) F_{w v}^{\prime}+\sum_{n} f_{n}^{\prime \prime} F_{n}^{\prime \prime}+\sum_{R c}\left(l t_{R c}^{\prime \prime} f_{R c}^{\prime \prime}\right) F_{R c}^{\prime \prime \prime} \\
& +\sum_{s} p s_{s}\left(\sum_{i} \sum_{m} \sum_{w} \sum_{k} c t_{i m w k} L_{i m w k s}+\sum_{i} \sum_{w} \sum_{j} \sum_{k} c t_{i w j k}^{\prime} L_{i w j k s}^{\prime}\right. \\
& +(1+\beta) \sum_{m} \sum_{R c} \sum_{r} c t_{r m R c}^{\prime \prime \prime} Q_{r m R c s}^{\prime}+\sum_{i} \sum_{m} \sum_{j} \sum_{k} c t_{i m j k}^{\prime \prime} L_{i m j k s}^{\prime \prime} \\
& +\sum_{i} \sum_{m} \sum_{h} c m_{i m h} Q_{i m h s}+\sum_{r} \sum_{m} \sum_{R c} c m_{r R c}^{\prime} Q_{r m R c s}^{\prime} \\
& \left.+\sum_{r} \sum_{n} \sum_{m} c s_{r n m} R_{r n m s}+\sum_{i} \sum_{j} p c_{i j} O_{i j s}+\pi_{s} E_{s}\right) \\
& m a x Z 2=\left(1-\left(\left(1-\left(1-\prod_{n}\left(1-\left(R F_{n}^{\prime \prime} * F_{n}^{\prime \prime}\right)\right)\right)\right)\right.\right. \\
& \left.\left.*\left(1-\left(1-\prod_{R c}\left(1-\left(R F_{R c}^{\prime \prime \prime} * F_{R c}^{\prime \prime \prime}\right)\right)\right)\right)\right)\right) *\left(1-\left(\left(1-\left(1-\prod_{m} \prod_{h} \prod_{u}\left(1-\left(R F_{m h u} * F_{m h u}\right)\right)\right.\right.\right.\right. \\
& \left.\left.*\left(1-\left(1-\prod_{w} \prod_{v}\left(1-\left(R F_{w v}^{\prime} * F_{w v}^{\prime}\right)\right)\right)\right)\right)\right) \\
& *\left(\sum _ { s } p s _ { s } \left(1-\left(\left(1-\left(1-\prod_{m} \prod_{w} \prod_{k}\left(1-\left(R K_{k} * G_{m w k s}\right)\right)\right)\right)\right.\right.\right. \\
& *\left(1-\left(1-\prod_{w} \prod_{j} \prod_{k}\left(1-\left(R K_{k} * G_{w j k s}^{\prime}\right)\right)\right)\right) *\left(1-\left(1-\prod_{m} \prod_{j} \prod_{k}\left(1-\left(R K_{k} * G_{m j k s}^{\prime \prime}\right)\right)\right)\right.
\end{aligned}
$$

The first objective function (7) of the model is to minimize supply chain costs. These costs include, respectively, fixed costs for the construction of factories and warehouses, fixed costs for supplier selection, the fixed cost of the construction of recycling centers, the expected values of transportation costs between different departments, The cost of lack, and cost of carbon credits. The second objective function (8) is to maximize the reliability of the entire system, including the reliability of suppliers, factories, warehouses, recycling centers, and vehicles.

$$
\begin{aligned}
& \sum_{m} \sum_{h} \sum_{u} f_{m h u} F_{m h u}+\sum_{w} \sum_{v} f_{w v}^{\prime} F_{w v}^{\prime}+\sum_{R c} f_{R c}^{\prime \prime \prime} F_{R c}^{\prime \prime \prime} \leq b \\
& \sum_{h} \sum_{u} F_{m h u} \leq 1 \quad \forall m \\
& \sum_{i} F_{w v}^{\prime} \leq 1 \quad \forall w \\
& \sum_{i} \sum_{m} \sum_{w} \sum_{k} e t_{i m w k} L_{i m w k s}+\sum_{i} \sum_{m} \sum_{w} \sum_{k} e t_{i w j k}^{\prime} L_{r m R c s}^{\prime}+\sum_{i} \sum_{m} \sum_{j} \sum_{k} e t_{i m j k}^{\prime \prime} L_{i m j k s}^{\prime \prime} \\
& +(1+\beta) \sum_{m} \sum_{r} \sum_{R c} e t_{r m R c}^{\prime \prime \prime} Q_{r m R c s}^{\prime}+\sum_{i} \sum_{m} \sum_{h} e m_{i m h} Q_{i m h s}-c a p=E_{s} \quad \forall s \\
& \sum_{i} \rho_{i h} Q_{i m h s} \leq \sum_{u} c_{m h u} F_{m h u} \quad \forall m, h, s \\
& \sum_{i} \sum_{m} \sum_{k} \rho_{i}^{\prime} L_{i m w k s} \leq \sum_{v} c_{w v}^{\prime} F_{w v}^{\prime} \quad \forall w, s \\
& \sum_{m} R_{r n m s} \leq c_{r n}^{\prime \prime} F_{r n}^{\prime \prime} \quad \forall r, n, s
\end{aligned}
$$




$$
\begin{aligned}
& \sum_{i} \sum_{h} \alpha_{r i} Q_{i m h s}=\sum_{n} R_{r n m s}+\beta \sum_{R c} Q_{r m R c s}^{\prime} \quad \forall r, m, s \\
& \sum_{h} Q_{i m h s}=\sum_{w} \sum_{k} L_{i m w k s}+\sum_{j} \sum_{k} L_{i m j k s}^{\prime \prime} \quad \forall i, m, s \\
& \sum \sum L_{i m w k s}=\sum \sum L_{i m w j k s}^{\prime} \quad \forall i, w, s \\
& \sum_{w} \sum_{k} L_{i w j k s}^{\prime}+\sum_{m} \sum_{k} L_{i m j k s}^{\prime \prime}+O_{i j s}=d_{i j s} \quad \forall i, j, s \\
& l b_{m w k} G_{m w k s} \leq \sum_{i} \rho_{i}^{\prime} L_{i m w k s} \leq u b_{m w k} G_{m w k s} \quad \forall m, w, k, s \\
& l b_{w j k}^{\prime} G_{w j k s}^{\prime} \leq \sum_{i} \rho_{i}^{\prime} L_{i w j k s}^{\prime} \leq u b_{w j k}^{\prime} G_{w j k s}^{\prime} \quad \forall w, j, k, s \\
& l b_{m j k}^{\prime \prime} G_{m j k s}^{\prime \prime} \leq \sum_{i} \rho_{i}^{\prime} L_{i m j k s}^{\prime \prime} \leq u b_{m j k}^{\prime \prime} G_{m j k s}^{\prime \prime} \quad \forall m, j, k, s \\
& \sum_{R c} Q_{r m R c s}^{\prime}=\lambda \sum_{n} R_{r n m s} \quad \forall m, r, s \\
& Q_{r m R c s}^{\prime} \leq F_{R c}^{\prime \prime \prime} M \quad \forall r, m, R c, s \\
& F_{m h u}, F_{w v}^{\prime}, F_{n}^{\prime \prime}, F_{R c}^{\prime \prime \prime}, G_{m w k s}, G_{w j k s}^{\prime}, G_{m j k s}^{\prime \prime} \in\{0,1\} \quad \forall m, h, u, w, n, R c, k, s, j \\
& Q_{i m h s}, Q_{r m R c s}^{\prime}, R_{r n m s}, L_{i m w k s}, L_{i w j k s}^{\prime}, L_{i m j k s}^{\prime \prime}, O_{i j s} \geq 0 \quad \forall i, m, h, R c, s, r, n, m, s, w, k, j \\
& E_{S} \text { is URS } \forall S
\end{aligned}
$$

Constraint (9) is a budget constraint for the construction of factories, warehouses, and recycling centers. Under constraints (10) and (11), more than one facility cannot be established in any location. In constraint (12), the amount of carbon generated in each scenario obtained. Constraints (13) and (14) are the capacity constraints of factories and warehouses. Constraint (15) is a raw material constraint. Factory requirements for raw materials are guaranteed under the constraint (16). Constraint (17-22) are limitations on the flow of goods between different supply chain segments. Constraint (23) shows the amount of waste generated from raw materials, and constraint (24) states that if recycling performed, recycling centers must be established beforehand. Constraints (25-27) state the type of variables.

\section{Solving method}

In multi-objective issues, goals may be conflicting, and have no dominancy to the others, so it is impossible to meet all of them at a time optimally. The main difference between multi-objective optimization and traditional single-objective optimization techniques can summarize in optimizing the objective functions simultaneously; And instead of a mathematically unique optimal solution, there is a set of optimal solutions equally suited.

In Pareto's optimization, instead of trying to find a solution, a set of acceptable answers are generated that decision maker can choose them. A set of all optimal solutions that are not dominated by any other 
solution is known as the optimal set of Pareto (Soroudi, 2017). The proposed problem is a nonlinear mixed integer model (MINLP).

The meta-heuristic algorithm, NSGAII is used to solve the model in large scale similar to the case which Liao et al. (2011) applied in uncertain supply chain design. Pareto answers compared with the definitive answers obtained from the GAMS software and epsilon constraint method with SCIP solver. To solve the problem, we used a computer with an Intel i5 processor with 4GB of RAM and 64-bit Windows.

\section{Numerical examples}

As numerical examples, several models have been produced and tested in different sizes. Our problem assumptions are similar to the model presented by Rezaei et al. (2017). They examined the case company named $\mathrm{ABC}$ that is employed in the production, assembly, and distribution of a wide range of office furniture in Australia. Problem parameters are generated randomly from the uniform distribution. There are three different types of product (portfolio) that should reach the top five consumers located in five various states of New South Wales, South Australia, Western Australia, Victoria, and Queensland.

Three suppliers are available to supply the raw materials required by the factories in South Australia, Western Australia, and Queensland. Three types of manufacturing technology can be used to produce each product. Using newer technology creates less pollution and brings more cost. The warehouses can be built in small and large sizes, and factories have three different capacities. There are up to three types of vehicles with different prices and pollution for distribution.

To analyze randomly, according to market performance, demand for products is assumed in optimistic and pessimistic. There are two predefined modes for carbon pricing as: low and high. Hence, we confront two or four scenarios in every case. In order to diversify and better analyze in model performance, we consider several modes for the number of possible locations for the construction of factories, warehouses, and recycling centers in different scenarios that are expressed in Table 2.

The reliability of each component is created randomly using a uniform distribution between 0.6 up to 0.99. In Table 3, the results are presented extensively in detail. In this table, the mean and standard deviation are equal to the mean value and the standard deviation of each of the target functions for nondominated answers. The NNDS describes the number of non-dominate solutions obtained from every solving methods.

As the GAMS is not effective to solve large-scale models in such cases some parts are marked with a dash. Fig. 2 depicts a Pareto front obtained by the exact method and the NSGA-II algorithm for the two generated examples. In this graph, the horizontal axis signifies the value of the first objective function (thousand) and the vertical axis denotes the value of the second objective function.

Table 2

Possible location for factory, warehouse, recycling center

\begin{tabular}{ccccccccccc}
\hline & P1 & P2 & P3 & P4 & P5 & P6 & P7 & P8 & P9 & P10 \\
\hline Factory & 2 & 2 & 3 & 3 & 4 & 4 & 6 & 6 & 8 & 8 \\
Warehouse & 2 & 2 & 3 & 3 & 3 & 3 & 4 & 4 & 5 & 5 \\
Recycling Center & 1 & 1 & 2 & 2 & 2 & 2 & 3 & 3 & 3 & 3 \\
Scenario & 2 & 4 & 2 & 4 & 2 & 4 & 2 & 4 & 2 & 4 \\
\hline
\end{tabular}


Table 3

Results and performance measures for both solutions in different sizes

\begin{tabular}{ccccccc}
\hline Sample & & Mean & Standard Deviation & NNDS & Lower Bound & Upper Pound \\
\hline \multirow{2}{*}{ P1 } & Gams & $(14924.58,0.7888)$ & $(7607.98,0.1947)$ & 4 & $(5301.15,0.5222)$ & $(24548.00,0.9933)$ \\
& NSGA-II & $(14914.87,0.8218)$ & $(4332.48,0.1227)$ & 4 & $(7745.15,0.6091)$ & $(19363.11,0.8951)$ \\
P2 & Gams & $(10082.62,0.7633)$ & $(4845.92,0.1244)$ & 4 & $(7021.17,0.5929)$ & $(18457.57,0.9198)$ \\
& NSGA-II & $(10940.86,0.8818)$ & $(1775.02,0.0802)$ & 10 & $(8865.56,0.6500)$ & $(14724.57,0.9262)$ \\
P3 & Gams & $(16783.91,0.7787)$ & $(15341.88,0.1976)$ & 3 & $(5448.27,0.5051)$ & $(38473.20,0.9648)$ \\
& NSGA-II & $(16291.74,0.7923)$ & $(7282.52,0.1108)$ & 6 & $(8497.75,0.5756)$ & $(27829.71,0.9137)$ \\
P4 & Gams & $(25831.12,0.9248)$ & $(14869.54,0.0548)$ & 6 & $(9283.85,0.8478)$ & $(53961.49,0.9996)$ \\
& NSGA-II & $(25634.34,0.8933)$ & $(17143.87,0.0858)$ & 9 & $(9453.16,0.7401)$ & $(53422.52,0.9924)$ \\
P5 & Gams & $(61274.01,0.8876)$ & $(36832.92,0.1833)$ & 5 & $(14159.71,0.5118)$ & $(103514.41,0.9892)$ \\
& NSGA-II & $(59431.18,0.8971)$ & $(36845.06,0.1573)$ & 7 & $(14219.63,0.5262)$ & $(105774.29,0.9994)$ \\
P6 & Gams & $(60601.86,0.9404)$ & $(41816.53,0.065)$ & 4 & $(19511.65,0.8305)$ & $(122998.10,0.9998)$ \\
& NSGA-II & $(57530.98,0.9389)$ & $(38946.41,0.0562)$ & 6 & $(15062.49,0.8457)$ & $(118583.35,0.9995)$ \\
\hline \multirow{2}{*}{ P7 } & Gams & - & - & - & - & - \\
& NSGA-II & $(108445.99,0.9216)$ & $(91637.16,0.0827)$ & 9 & $(23210.07,0.7454)$ & $(222284.260 .9999)$ \\
P8 & Gams & - & - & - & - & - \\
& NSGA-II & $(102810.38,0.9359)$ & $(71308.92,0.0831)$ & 7 & $(27993.42,0.7392)$ & $(187084.50,0.9999)$ \\
& Gams & - & - & - & - & - \\
& NSGA-II & $(174131.66,0.9306)$ & $(181490.68,0.0583)$ & 8 & $(28882.02,0.8239)$ & $(420282.95,0.9999)$ \\
& Gams & - & - & - & - & - \\
& NSGA-II & $(175804.07,0.8964)$ & $(143617.36,0.0885)$ & 8 & $(27821.18,0.7942)$ & $(351971.85,0.9999)$ \\
\hline
\end{tabular}
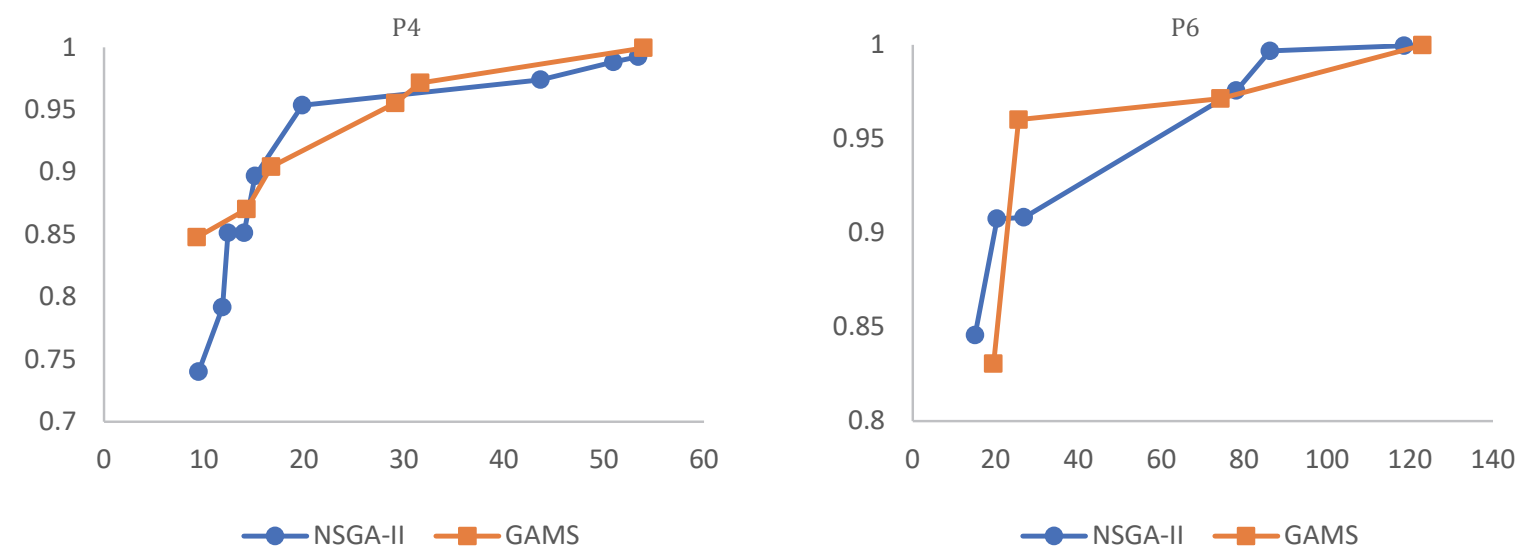

Fig. 2. Pareto front in two different sizes

\section{Sensitivity analysis}

Here the sensitivity analysis based on the waste of the production, carbon emission, penalties for extra carbon contamination and the relation between material supplying purchase cost and recycling centers will be presented in details:

\subsection{Sensitivity analysis on waste production}

For the case of increasing waste or rejected products, the optimal solution will have tendency to establishment of recycling centers. As we are looking for strategies to reduce costs in the model, if the waste is negligible, there is no need to establish recycling centers. Through Fig. 3, The percentage of recycling is in coordination with the number of founded recycling centers. 


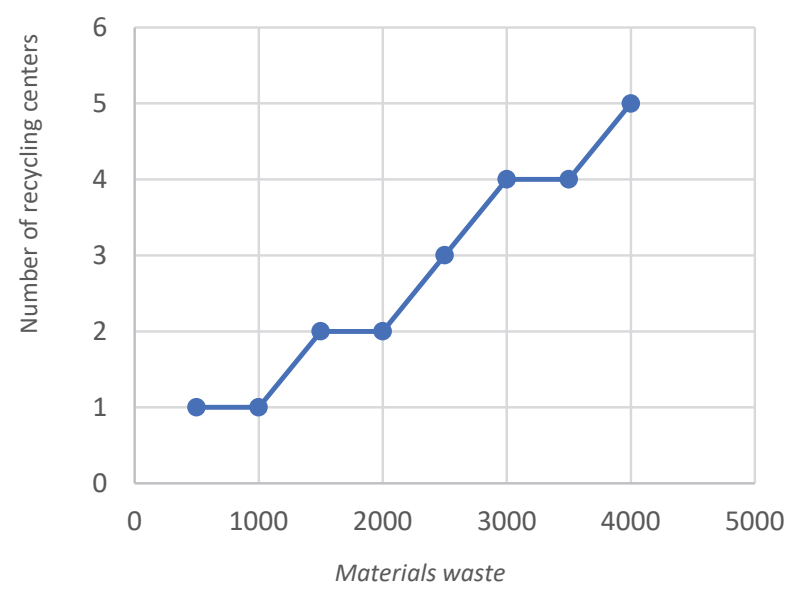

Fig. 3. The coordination of recycling centers and the percentage of waste materials

\subsection{Permissible capacity for carbon contaminations}

In this case carbon is emitted by factories, recycling centers, and transportation. If the capacity level decreases, it will have the most significant impact on recycling centers. Due to capacity reduction, the model seeks to find carbon emissions centers. As the activity of the recycling centers has the direct effect on carbon emission, with the reduction of capacity, the potential for the establishment of recycling centers decreases. However, if penalties for additional carbon emissions reduced, the probability of the construction of recycling centers increases as it is obvious in Fig. 4.

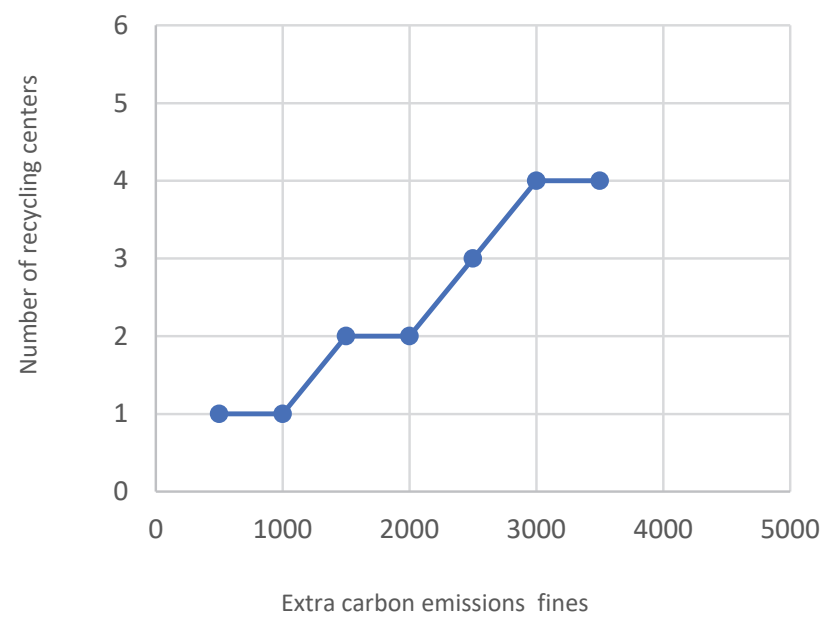

Fig. 4. The relationship between penalty for extra carbon emissions and the number of recycling centers

\subsection{The cost of purchasing raw materials}

If the purchase price of raw materials is reduced, the model does not have a particular desire to establish recycling centers because the cost of waste recycling is not significantly different from the purchase of raw materials which is clear in Fig. 5. 


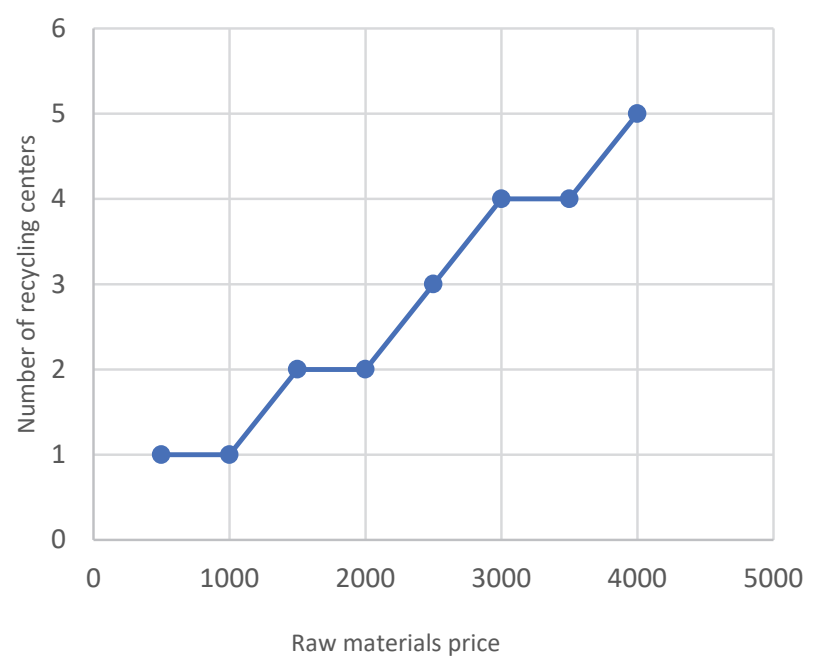

Fig. 5. Dependency between the price of raw materials and the number of recycling centers

\section{Conclusion and future researches}

This paper has provided an investigation of supply chain reliability in a four-echelon closed-loop supply chain network based on structural reliability analysis. It presents a stochastic model in two-stage that can be used to design and analyze supply chain sustainability. In this model for being closer to the reality, carbon prices and product demand are considered stochastic. Here we have proposed a biobjective model that maximizes reliability and minimizes costs, formulated by mixed-integer nonlinear programming. To illustrate the efficiency of the model and the meta-heuristic algorithm in solving this problem, numerical examples have been used in different sizes and finally the derived Pareto front and performance metrics indicate the ability of the proposed algorithm.

The reliability objective function used to determine the acceptable level of reliability. By increasing costs, build more centers, and using more resources, the reliability of the system increases. Given the uncertain nature of the real world, attention to risk and reliability can bring our theoretical perspective closer to the real world. Also, considering recycling centers to reduce environmental damage in the green supply chain and maximizing total supply chain reliability besides reducing entire costs are as innovations of this study.

By considering recycling centers, the factory's waste is recycled and turned back to the manufacturing process. Through solving and analyzing the model, it was found that the establishment of recycling centers will be more efficient when the higher amount of waste caused by production. Also, with increasing raw material prices, the founding of recycling centers will be crucial. As well as one of the carbon producers is recycling centers, allowed carbon capacity has the most significant impact on recycling centers. By decreasing the capacity, the possibility of founding recycling centers will be reduced.

Future research in this field can include more extensive supply chain networks and use other empirical scenarios that involve resource utilization. Also, uncertainty about the amount of carbon emissions in various production or transportation modes could be a field area for future study. The evolution of the multi-period supply chain outlining models by multi-stage stochastic planning could be of our suggestions. 


\section{References}

Abdallah, T., Farhat, A., Diabat, A., \& Kennedy, S. (2012). Green supply chains with carbon trading and environmental sourcing: Formulation and life cycle assessment. Applied Mathematical Modelling, 36(9), 4271-4285.

Atoei, F., Teimory, E., \& Amiri, A. (2013). Designing reliable supply chain network with disruption risk. International Journal of Industrial Engineering Computations, 4(1), 111-126.

Baghalian, A., Rezapour, S., \& Farahani, R. Z. (2013). Robust supply chain network design with service level against disruptions and demand uncertainties: A real-life case. European Journal of Operational Research, 227(1), 199-215.

Bidhandi, H. M., \& Yusuff, R. M. (2011). Integrated supply chain planning under uncertainty using an improved stochastic approach. Applied Mathematical Modelling, 35(6), 2618-2630.

Birge, J. R., \& Louveaux, F. (2011). Introduction to stochastic programming. Springer Science \& Business Media.

Chalmardi, M. K., \& Camacho-Vallejo, J. F. (2019). A bi-level programming model for sustainable supply chain network design that considers incentives for using cleaner technologies. Journal of Cleaner Production, 213, 1035-1050.

Daehy, Y., Krishnan, K., Alsaadi, A., \& Alghamdi, S. (2019). Effective cost minimization strategy and an optimization model of a reliable global supply chain system. Uncertain Supply Chain Management, 7(3), 381-398.

Dehghanian, F., \& Mansour, S. (2009). Designing sustainable recovery network of end-of-life products using genetic algorithm. Resources, Conservation and Recycling, 53(10), 559-570.

Fahimnia, B., Sarkis, J., \& Davarzani, H. (2015). Green supply chain management: A review and bibliometric analysis. International Journal of Production Economics, 162, 101-114.

Guillén-Gosálbez, G., \& Grossmann, I. E. (2009). Optimal design and planning of sustainable chemical supply chains under uncertainty. AIChE Journal, 55(1), 99-121.

Ha, C., Jun, H. B., \& Ok, C. (2018). A mathematical definition and basic structures for supply chain reliability: A procurement capability perspective. Computers \& Industrial Engineering, 120, 334345.

Hamidieh, A., Arshadikhamseh, A., \& Fazli-Khalaf, M. (2018). A robust reliable closed loop supply chain network design under uncertainty: A case study in equipment training centers. International Journal of Engineering, Transactions B: Applications, 31(4), 648-658.

Hugo, A., \& Pistikopoulos, E. N. (2005). Environmentally conscious long-range planning and design of supply chain networks. Journal of Cleaner Production, 13(15), 1471-1491.

Jerbia, R., Boujelben, M. K., Sehli, M. A., \& Jemai, Z. (2018). A stochastic closed-loop supply chain network design problem with multiple recovery options. Computers \& Industrial Engineering, 118, 23-32.

Kuo, T. C., Tseng, M. L., Chen, H. M., Chen, P. S., \& Chang, P. C. (2018). Design and analysis of supply chain networks with low carbon emissions. Computational Economics, 52(4), 1353-1374.

Liao, S. H., Hsieh, C. L., \& Lin, Y. S. (2011). A multi-objective evolutionary optimization approach for an integrated location-inventory distribution network problem under vendor-managed inventory systems. Annals of Operations Research, 186(1), 213-229.

Melo, M. T., Nickel, S., \& Saldanha-Da-Gama, F. (2009). Facility location and supply chain management-A review. European Journal of Operational Research, 196(2), 401-412.

Nickel, S., Saldanha-da-Gama, F., \& Ziegler, H. P. (2012). A multi-stage stochastic supply network design problem with financial decisions and risk management. Omega, 40(5), 511-524.

Nosrati, M., \& Arshadi-Khamseh, A. (2020). Bi objective hybrid vehicle routing problem with alternative paths and reliability. Decision Science Letters, 9(2), 145-162.

Ramudhin, A., Chaabane, A., \& Paquet, M. (2010). Carbon market sensitive sustainable supply chain network design. International Journal of Management Science and Engineering Management, 5(1), 30-38. 
Rezaee, A., Dehghanian, F., Fahimnia, B., \& Beamon, B. (2017). Green supply chain network design with stochastic demand and carbon price. Annals of Operations Research, 250(2), 463-485.

Singh, S., Jain, S., \& Pareek, S. (2014). An economic production model for time dependent demand with rework and multiple production setups. International Journal of Industrial Engineering Computations, 5(2), 305-314.

Soroudi, A. (2017). Power system optimization modeling in GAMS (Vol. 78). Switzerland: Springer.

Torabi, N., Tavakkoli-Moghaddam, R., \& Najafi, E. (2019). A Two-Stage Green Supply Chain Network with a Carbon Emission Price by a Multi-Objective Interior Search Algorithm. International Journal of Engineering, 32(6), 828-834.

Tsao, Y. C., Thanh, V. V., Lu, J. C., \& Yu, V. (2018). Designing sustainable supply chain networks under uncertain environments: Fuzzy multi-objective programming. Journal of Cleaner Production, 174, 1550-1565.

Zaitsev, E. (2012). Supply chain reliability modelling. LogForum, 8(1), 61-69.

Zakeri, A., Dehghanian, F., Fahimnia, B., \& Sarkis, J. (2015). Carbon pricing versus emissions trading: A supply chain planning perspective. International Journal of Production Economics, 164, 197-205.

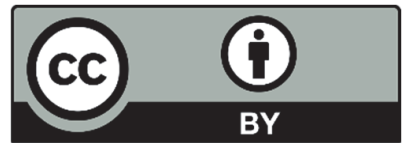

(C) 2020 by the authors; licensee Growing Science, Canada. This is an open access article distributed under the terms and conditions of the Creative Commons Attribution (CC-BY) license (http://creativecommons.org/licenses/by/4.0/). 